\title{
Structural Characteristics and Optical Properties of Thermally Oxidized Zinc Films
}

\author{
D.I. Rusu*, G.G. Rusu and D. LuCA \\ Faculty of Physics, "Al. I. Cuza" University, 11 Carol I Blvd., 700506 Iasi, Romania \\ (Received October 24, 2010; revised version February 10, 2011; in final form March 10, 2011)
}

\begin{abstract}
Zinc oxide $(\mathrm{ZnO})$ thin films (with thickness ranged from $780 \mathrm{~nm}$ to $1150 \mathrm{~nm}$ ) were prepared by thermal oxidation in air (at 600-700 K, for 20-30 min) of vacuum evaporated metallic zinc films. The Zn films were deposited on glass substrates at room temperature. The crystalline structure of $\mathrm{ZnO}$ thin film samples was investigated using X-ray diffraction technique. The diffraction patterns revealed that the $\mathrm{ZnO}$ thin films were polycrystalline and have a wurtzite (hexagonal) structure. The film crystallites are preferentially oriented with (002) planes parallel to substrate surface. Some important structural parameters (lattice parameters of the hexagonal cell, crystallite size, $\mathrm{Zn}-\mathrm{O}$ bond length, residual stress, etc.) of the films were determined. The surface morphology of the prepared $\mathrm{ZnO}$ thin films, investigated by atomic force microscopy, revealed a uniform columnar structure. The spectral dependence of transmission coefficient has been studied in the wavelength range from $300 \mathrm{~nm}$ to $1700 \mathrm{~nm}$. The optical energy band gap calculated from the absorption spectra (supposing allowed direct band-to-band transitions) are in the range 3.17-3.19 eV. The dependence of the microstructural and optical characteristics on the preparation conditions (oxidation temperature, oxidation time, etc.) of the oxidized zinc films is discussed.
\end{abstract}

PACS: 77.55.hf, 68.55.-a, 68.55.J-, 81.15.Aa, 78.20.-e

\section{Introduction}

Due to their wide direct optical band gap (about $3.37 \mathrm{eV}$ at room temperature), high transmission coefficient $(>80 \%)$ in the visible and near infrared spectral range, high electrical conductivity, important piezoelectric and photoelectric properties (e.g. large exciton binding energy of $60 \mathrm{meV}$ at $300 \mathrm{~K})$ [1-8], zinc oxide $(\mathrm{ZnO})$ thin films and nanostructures have an increasing role in modern solid state device technology (transparent field effect transistors, light emitting diodes, gas sensors, solar cells, transparent conducting electrodes, electronics in ultraviolet and blue spectral ranges, etc.) [1, 2, 9-13].

A significant progress in the preparation technology of films and heterostructures based on $\mathrm{ZnO}$ has been observed in the last years $[1,5-8]$.

Many techniques have been used in order to prepare high-quality $\mathrm{ZnO}$ thin films, including magnetron sputtering, molecular beam epitaxy, pulsed laser deposition, spray pyrolysis, spin coating, chemical vapor deposition, etc. $[3-6,14-17]$.

Few information relating to $\mathrm{ZnO}$ thin films prepared by thermal oxidation of metallic zinc films are reported in literature [5-8]. Thermal dry oxidation (oxidation in oxygen ambient) is the most frequently used method of oxide formation during this process. It is however well known that structural, electronic transport and optical properties of $\mathrm{ZnO}$ thin films strongly depend both on structural characteristics of metallic zinc films (which, in their turn, depend on the deposition parameters) and on

* corresponding author; e-mail: d_i_rusu@yahoo.com the oxidation conditions (oxidation temperature, heating rate, oxidation time, etc.).

It was shown that the use of thermal oxidation of zinc films for producing $\mathrm{ZnO}$ thin films is recommended because this is low-cost method which provides the possibility of obtaining stoichiometric and homogeneous films, doped films and $\mathrm{ZnO}$ films with large thickness.

An important number of experimental results are, at present, obtained by using thin films with lower thicknesses (usually, less than $200 \mathrm{~nm}$ ). As compared with other methods, the oxidation of the metallic zinc films has some important advantages: simplified deposition process, the possibility of controlling structural characteristics, processing of multilayered structures, etc. [5-7].

In the present paper we report on the structural and optical characteristics of the $\mathrm{ZnO}$ thin films prepared by thermal oxidation in air of metallic zinc films. Some correlations between the film structure, optical properties of $\mathrm{ZnO}$ films and their preparation conditions were established.

\section{Experimental}

Metallic zinc thin films were deposited onto glass (Corning 2947) substrates by thermal evaporation under vacuum (using the quasi-closed volume technique [18]). The material for evaporation was metallic zinc powder having a purity of $99.993 \%$. Zinc oxide thin films were prepared by thermal oxidation (in open atmosphere at relative humidity about $60 \%$ ) of as-deposited zinc metallic thin films.

Before deposition, the substrates were cleaned with chromic acid, ethanol and double-distilled deionized water. Finally, they were dried in vacuum at temperature 
of $600 \mathrm{~K}$ for $1 \mathrm{~h}$. More details on the deposition equipment have been described in detail in our previous papers [7, 18, 19].

The following values of deposition parameters were used: evaporator (source)-substrate distance, $d_{\mathrm{es}}=$ $8 \mathrm{~cm}$; source temperature, $T_{\mathrm{ev}}=700 \mathrm{~K}$; deposition rate, $r_{\mathrm{d}}=13-14 \AA / \mathrm{s}$; substrate temperature, $T_{\mathrm{s}}=300 \mathrm{~K}$. These parameters are kept constant during the deposition for all zinc films referred in this paper.

The oxidation process consisted of the three successive technological steps: (i) heating of zinc films from room temperature to the oxidation temperature, $T_{0}\left(T_{0}\right.$ was varied between 600 and $700 \mathrm{~K}$, with increasing temperature rate of $6-8 \mathrm{~K} / \mathrm{min}$ ); (ii) annealing for a certain oxidation time $\tau_{0}\left(\tau_{0}=20-30 \mathrm{~min}\right)$ at oxidation temperature, $T_{0}$; (iii) cooling down from the oxidation temperature to room temperature with a temperature decreasing rate of 10-15 K/min. These oxidation conditions permit to prepare $\mathrm{ZnO}$ thin films with stable structure, stoichiometric and homogeneous composition and with good adhesion to the substrate.

The thickness of $\mathrm{ZnO}$ thin films (which ranged between $780 \mathrm{~nm}$ and $1150 \mathrm{~nm}$ ), was determined by an interferometric method (multiple-beam Fizeau's fringe method [13] by the reflection of a monochromatic light-beam with $\lambda=550 \mathrm{~nm}$ ).

The crystalline structure of $\mathrm{ZnO}$ films was analysed by X-ray diffraction (XRD) technique, using $\mathrm{Cu} K_{\alpha}$ radiation $(\lambda=1.5418 \AA)$ in the $2 \theta$ range from $20^{\circ}$ to $90^{\circ}$ $[20,21]$.

The surface microstructure of the films was examined by an ex situ atomic force microscopy (AFM). The AFM images were acquired in the tapping mode and in the repulsive force regime.

The optical reflection and transmission coefficients were recorded at room temperature, within the wavelength range from $300 \mathrm{~nm}$ to $1700 \mathrm{~nm}$ using a TEC-5 computer controlled spectrometer.

The absorption coefficient, $\alpha_{\lambda}$, was determined from the expression [22, 23]

$$
\alpha_{\lambda}=\frac{1}{d} \ln \frac{\left(1-R_{\lambda}\right)^{2}}{T_{\lambda}},
$$

where $d$ denotes the film thickness, $T_{\lambda}$ and $R_{\lambda}$ are the transmission and reflection coefficients at wavelength $\lambda$, respectively.

\section{Results and discussion}

\subsection{Microstructural characteristics}

The XRD patterns were used for identification of crystalline phases and microstructural analysis of the prepared $\mathrm{ZnO}$ thin films. Figures 1 and 2 show the representative XRD patterns.

In order to establish the influence of the structural characteristics of vacuum evaporated $\mathrm{Zn}$ thin films on the structure of $\mathrm{ZnO}$ thin films, the following experimental procedure was used: in the similar deposition conditions, two series of thin-film samples were obtained. The structure of first series was investigated by XRD technique immediately after deposition and the second series was submitted to a thermal oxidation (oxidation conditions were presented in Table I) and then was studied by XRD analysis.

TABLE I

Oxidation conditions and values of texture coefficient for $\mathrm{ZnO}$ thin films.

\begin{tabular}{c|c|c|c|c|c|c}
\hline \hline \multirow{2}{*}{ Sample } & \multirow{2}{*}{$\begin{array}{c}d \\
T_{0}\end{array}$} & \multirow{2}{*}{$\tau_{0}$} & \multicolumn{3}{|c}{$T C(h k l)[\%]$} \\
\cline { 5 - 7 } & {$[\mathrm{nm}]$} & {$[\mathrm{K}]$} & {$[\mathrm{min}]$} & $(100)$ & $(002)$ & $(101)$ \\
\hline OXZ.60.07 & 780 & 600 & 20 & 0.23 & 2.49 & 0.56 \\
OXZ.60.09 & 900 & 600 & 20 & 1.35 & 2.03 & 1.08 \\
OXZ.70.10 & 1020 & 700 & 30 & 1.23 & 2.38 & 1.19 \\
OXZ.70.11 & 1150 & 700 & 30 & 1.47 & 2.16 & 1.30 \\
\hline
\end{tabular}

$d$, film thickness; $T_{0}$, oxidation (annealing) temperature; $\tau_{0}$, oxidation time; $T C(h k l)$, texture coefficient for $(h k l)$ peaks

The typical XRD patterns are shown in Figs. 1 and 2 . It can be observed from Fig. 1a that zinc films are polycrystalline and have a hexagonal close-packed structure. The reflection corresponding to the (002) planes become more evidenced. Therefore, the films crystallites are preferentially oriented with $c$-axis normal to substrate surface.

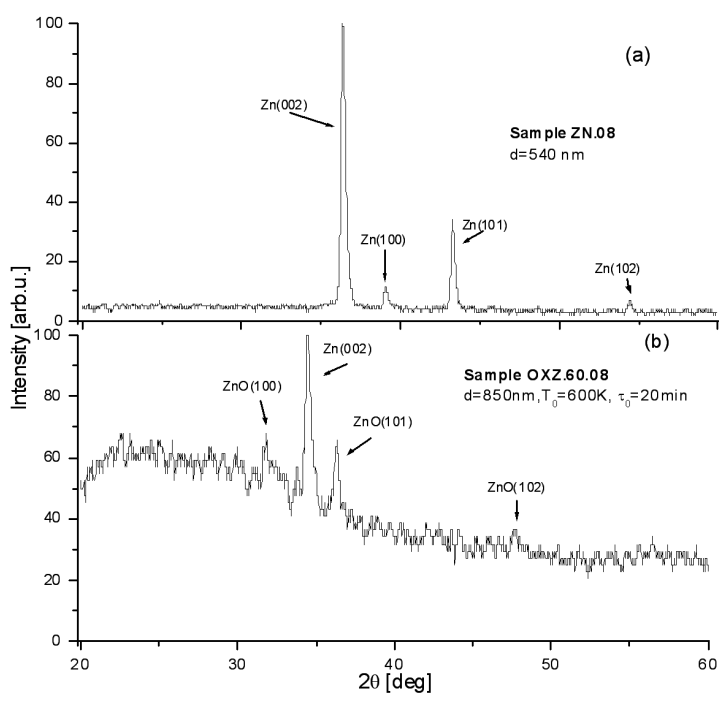

Fig. 1. XRD patterns for two investigated samples: (a) sample ZN.08 as-deposited zinc film (b) sample OXZ.60.08 oxidized at temperature $T_{0}=600 \mathrm{~K}$ for $\tau_{0}=20 \mathrm{~min}$.

Figure 2 presents XRD patterns for four $\mathrm{ZnO}$ films with different thickness, thermally oxidized in various conditions. The indexed diffraction peaks were used to calculate the interplanar spacings corresponding to the (100), (002) and (101) planes of the hexagonal (wurtzite) 


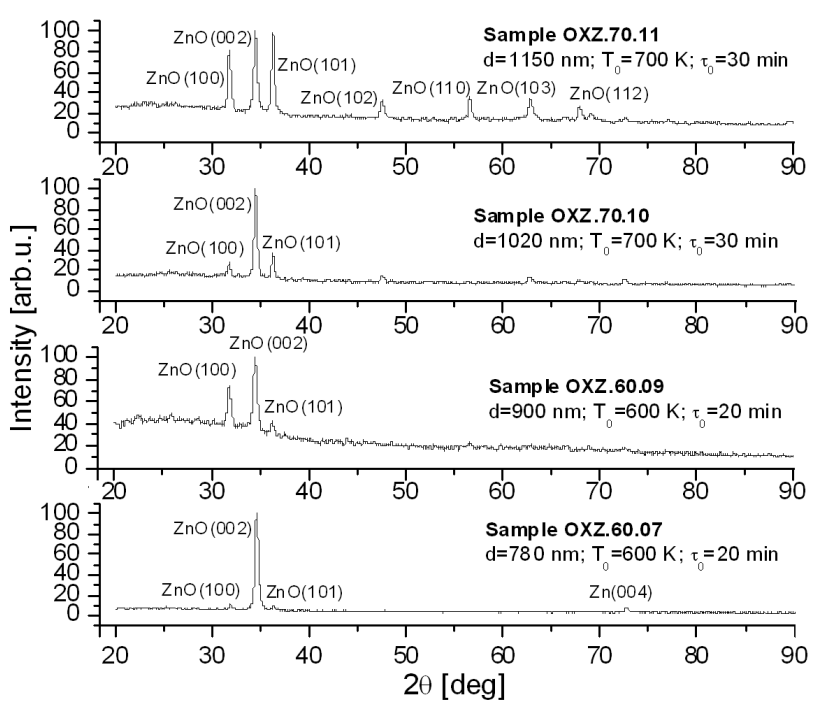

Fig. 2. The X-ray diffraction patterns of $\mathrm{ZnO}$ thin films with different thickness.

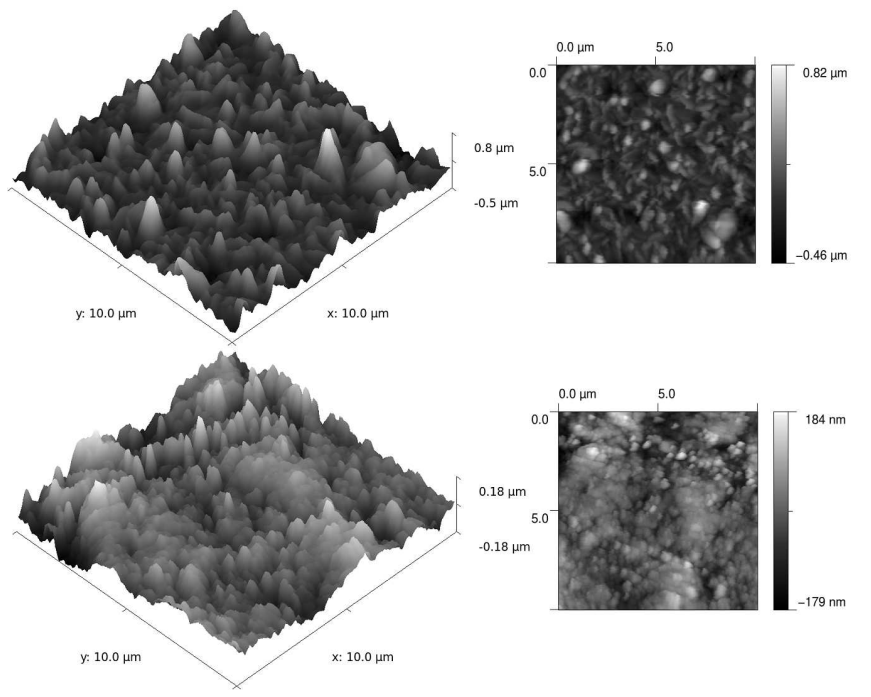

Fig. 3. AFM images (3D and 2D) for $\mathrm{ZnO}$ thin films with different thickness: (a) sample OXZ.60.07 $(d=$ $780 \mathrm{~nm} ; T_{0}=600 \mathrm{~K} ; t_{0}=20 \min ; R_{\mathrm{a}}=108 \mathrm{~nm} ;$ $\left.R_{\mathrm{rms}}=144 \mathrm{~nm}\right) ;(\mathrm{b})$ sample OXZ.70.11 $(d=1150 \mathrm{~nm}$; $\left.T_{0}=700 \mathrm{~K} ; t_{0}=30 \min ; R_{\mathrm{a}}=35 \mathrm{~nm} ; R_{\mathrm{rms}}=45 \mathrm{~nm}\right)$.

$\mathrm{ZnO}$ crystalline structure $[1,11,14-16]$. It can be observed that the diffraction patterns do not indicate the presence of zinc crystalline phase in $\mathrm{ZnO}$ films. Therefore, the used oxidation conditions provide growth of nearly stoichiometric $\mathrm{ZnO}$ films, having a single phase of $\mathrm{ZnO}$.

Structural investigations showed that the zinc oxide films prepared under the mentioned conditions are polycrystalline and have a wurtzite (hexagonal) structure [2-4]. For all $\mathrm{ZnO}$ films, crystallites are preferentially oriented with (002) planes parallel to the substrate sur- face. The $c$-axis of hexagonal cell is normal to substrate, resulting in columnar crystallites that are perpendicular to the substrate surface (this structure is confirmed by AFM images in Fig. 3). The (100) and (101) planes are also evidenced in the XRD patterns.

TABLE II

Structural characteristics of zinc films and zinc oxide films.

\begin{tabular}{c|c|c|c|c|c|c|c}
\hline \hline Sample & $\begin{array}{c}d \\
{[\mathrm{~nm}]}\end{array}$ & $\begin{array}{c}T_{0} \\
{[\mathrm{~K}]}\end{array}$ & $\begin{array}{c}\tau_{0} \\
{[\mathrm{~min}]}\end{array}$ & $\begin{array}{c}2 \theta \\
{[\text { degree }]}\end{array}$ & $(h k l)$ & $\begin{array}{c}a \\
{[\AA]}\end{array}$ & $\begin{array}{c}c \\
{[\AA]}\end{array}$ \\
\hline \multirow{2}{*}{ ZN.08 } & 540 & - & - & $\begin{array}{c}36.28 \\
39.00\end{array}$ & $\begin{array}{c}002 \\
100\end{array}$ & $\begin{array}{c}- \\
2.664\end{array}$ & - \\
\hline \multirow{2}{*}{ OXZ.60.08 } & \multirow{2}{*}{850} & \multirow{2}{*}{600} & 20 & 31.75 & 100 & 3.236 & - \\
& & & & 34.35 & 002 & - & 5.218 \\
\hline
\end{tabular}

$d$, film thickness: $T_{0}$, oxidation temperature; $\tau_{0}$, oxidation time; $\theta$, Bragg angle; $(h k l)$, Miller indices; $a$ and $c$, lattice parameters of the hexagonal (wurtzite) structure

Lattice parameters of $\mathrm{ZnO}$ wurtzite structure, $a$ and $c$, were calculated using a well-known analytical method [20]. Some structural characteristics of zinc film and zinc oxide film for one of our samples are shown in Table II. The obtained results for other samples are presented in Table III. For the ZnO films oxidized at higher temperature, these values, calculated using the (002) and (100) diffraction peaks, are slightly larger than standard values for $\mathrm{ZnO}$ polycrystalline powder $(a=3.249 \AA$, $c=5.201 \AA)[14,16]$. This fact can be explained as an effect of the oxygen depletion in the film during oxidation process $[14,16]$. The presence of other phases in $\mathrm{ZnO}$ system, as well of non-oxidized $\mathrm{Zn}$ atoms is not observed.

For the $\mathrm{ZnO}$ films obtained at lower oxidation temperature, the values of $c$-parameter of hexagonal cell (around $5.193 \AA$ ), calculated from the $(002)$ peak position are very close to the $c$-parameter values of the bulk $\mathrm{ZnO}$ crystals $[2,24]$, indicating that the films are displaying a low degree distortion due to the structural defects at film-substrate interface.

The average crystallite size were calculated from the Debye-Scherrer formula [20, 24]

$$
D=\frac{k \lambda}{\beta_{2 \theta} \cos \theta},
$$

where $k$ denotes the Scherrer constant (the shape factor of the average crystallite and can be considered $k=0.90$ $[25,26]) ; \lambda=1.5418 \mathrm{~nm}$ is the wavelength of the incident $\mathrm{Cu} K_{\alpha}$ radiation; $\beta_{2 \theta}$ represents the full-width at half-maximum of the respective peak and $\theta$ is the Bragg diffraction angle.

For some studied samples, the crystallite sizes, calculated from Eq. (2) are presented in Table III. The average size varied from $24.68 \mathrm{~nm}$ to $32.21 \mathrm{~nm}$. The films with greater thickness are characterized by greater crystallite size.

The $\mathrm{Zn}-\mathrm{O}$ bond length, $L$, was also calculated using the relation $[26,27]$ : 


$$
L=\left[\frac{a^{2}}{3}+\left(\frac{1}{2}-u\right)^{2} c^{2}\right],
$$

where the $u$ parameter for wurtzite structure can be expressed as [27]:

$$
u=\frac{a^{2}}{3 c^{2}}+0.25
$$

The values obtained for the bond length are indicated in Table III. It is known that ionic radius of $\mathrm{O}^{2-}$ is $1.38 \AA[26]$ and ionic radius of the $\mathrm{Zn}^{2+}$ is $0.83 \AA$ [2]. Consequently, the length of the $\mathrm{Zn}-\mathrm{O}$ bond is $2.21 \AA$. The small values obtained for our samples indicate the presence of the structural defects (especially, oxygen vacancies).

Structural parameters of the investigated $\mathrm{ZnO}$ thin films.

\begin{tabular}{|c|c|c|c|c|c|c|c|c|c|c|}
\hline Sample & $\begin{array}{c}d \\
{[\mathrm{~nm}]}\end{array}$ & $\begin{array}{c}r_{d} \\
{[\AA / \mathrm{s}]}\end{array}$ & $\begin{array}{c}T_{s} \\
{[\mathrm{~K}]} \\
\end{array}$ & $\begin{array}{l}T_{0} \\
{[K]} \\
\end{array}$ & $\begin{array}{c}\tau_{0} \\
{[\mathrm{~min}]}\end{array}$ & $\begin{array}{c}2 \theta \\
\text { [degree] }\end{array}$ & $(h k l)$ & $\begin{array}{c}d_{h k l} \\
{[\AA]}\end{array}$ & $\begin{array}{c}a \\
{[\AA]}\end{array}$ & $\begin{array}{c}c \\
{[\AA]}\end{array}$ \\
\hline OXZ.60.07 & 780 & 15 & 300 & 600 & 20 & 34.4 & 002 & 2.604 & - & 5.193 \\
\hline \multirow{2}{*}{ OXZ.60.09 } & \multirow{2}{*}{900} & \multirow{2}{*}{14} & \multirow{2}{*}{300} & \multirow{2}{*}{600} & \multirow{2}{*}{20} & 31.7 & 100 & 2.803 & 3.241 & - \\
\hline & & & & & & 34.4 & 002 & 2.592 & - & 5.192 \\
\hline \multirow{2}{*}{ OXZ.70.10 } & \multirow{2}{*}{1020} & \multirow{2}{*}{13} & \multirow{2}{*}{300} & \multirow{2}{*}{700} & \multirow{2}{*}{30} & 31.7 & 100 & 2.816 & 3.266 & - \\
\hline & & & & & & 34.4 & 002 & 2.603 & - & 5.208 \\
\hline \multirow{2}{*}{ OXZ.70.11 } & \multirow{2}{*}{1150} & \multirow{2}{*}{14} & \multirow{2}{*}{300} & \multirow{2}{*}{700} & \multirow{2}{*}{30} & 31.7 & 100 & 2.808 & 3.247 & - \\
\hline & & & & & & 34.4 & 002 & 2.607 & - & 5.204 \\
\hline
\end{tabular}

TABLE III

$d$, film thickness; $r_{\mathrm{d}}$, deposition rate; $T_{\mathrm{s}}$, substrate temperature; $T_{0}$, oxidation temperature; $\tau_{0}$, oxidation time; $\theta$, Bragg angle; $(h k l)$, Miller indices; $d_{h k l}$, interplanar spacing of $(h k l)$ planes; $a$ and $c$, lattice parameters of the hexagonal (wurtzite) structure

The values of some structural parameters of the studied $\mathrm{ZnO}$ thin films.

TABLE IV

\begin{tabular}{c|c|c|c|c|c|c|c|c|c}
\hline \hline \multirow{2}{*}{ Sample } & \multirow{2}{*}[\mathrm{nm}]{} & \multirow{2}{*}{$T_{0}[\mathrm{~K}]$} & \multirow{2}{*}{$\tau_{0}[\mathrm{~min}]$} & \multicolumn{3}{|c|}{$D[\mathrm{~nm}]$} & $c / a(002)$ & $L[\mathrm{~nm}]$ & $d_{\mathrm{c}}[\mathrm{nm}]$ \\
\hline OXZ.60.07 & 780 & 600 & 20 & 26.23 & - & - & 1.60 & 1.94 & 3.18 \\
OXZ.60.09 & 900 & 600 & 20 & 30.93 & 28.41 & 28.46 & 1.61 & 1.93 & 3.18 \\
OXZ.70.10 & 1020 & 700 & 30 & 27.97 & 24.68 & 26.97 & 1.60 & 1.94 & 3.19 \\
OXZ.70.11 & 1150 & 700 & 30 & 32.21 & 27.68 & 27.37 & 1.61 & 1.93 & 3.18 \\
\hline
\end{tabular}

$d$, film thickness; $T_{0}$, oxidation temperature; $\tau_{0}$, oxidation time; $D$, crystallite size (calculated taken into account indicated peaks of the wurtzite structure); $c / a$, ratio of lattice parameters; $L$, length of $\mathrm{Zn}-\mathrm{O}$ bond; $d_{\mathrm{c}}$, cation-cation distance

It is known that cation-cation distance for wurtzite structure $[28,29]$ is

$$
d_{\mathrm{c}}=c x\left(\frac{3}{8}\right)^{1 / 2},
$$

where $c$ is parameter of hexagonal (wurtzite) cell (the height of hexagonal prism).

For our samples, the obtained values of $d_{c}$ are lower than those reported for bulk $\mathrm{ZnO}$ crystals [29].

The preferred orientation of particular crystal planes relative to film substrate can be quantitatively evaluated using texture coefficient, $T C(h k l)$, which has been determined from expression $[30,31]$ :

$$
T C(h k l)=\frac{I(h k l) / I_{0}(h k l)}{(1 / n) \sum_{n} I(h k l) / I_{0}(h k l)},
$$

where $I(h k l)$ is intensity of the XRD peak corresponding to $(h k l)$ planes, $n$ is the number of the diffraction peaks taking into account, $I_{0}(h k l)$ denotes the intensity of the XRD peak reference of the randomly oriented crystallites. For some studied samples, the $T C(h k l)$ values for (002), (101) and (100) planes are listed in Table I, together with the oxidation conditions.

It can be observed that $T C(002)$ is greater than 2 for all samples. According to Eq. (6) if $T C(h k l)$ is equal to one for all the considered $(h k l)$ planes, then the films are characterized by a randomly crystallite orientation, similar to the standard (reference) JCPDS XRD pattern [21]. $T C(h k l)$ values higher than one show that a large number 
of crystallites are oriented with their $(h k l)$ planes parallel to substrate surface.

Table I also shows that film crystallites preferentially oriented with $c$-axis of hexagonal cell normal to the substrate surface are characterized by larger size. This behavior can be explained by supposing that these crystallites are present in early stages of film growth. It can be observed from XRD patterns (Fig. 2) that the films with lower thickness have a high intensity (002) peak. The $T C(h k l)$ values decrease with increasing oxidation temperature.

The texture coefficient depends on the film thickness. At smaller thickness, film crystallites are preferentially oriented with their $c$-axis perpendicular to the substrate surface. We observe that an increase of the oxidation time results in increase of the crystallite size.

The standard value of the $c / a$ ratio for the wurtzite structure is about 1.63. There is a good agreement between obtained values (Table III) and standard one. Therefore, it can be supposed that crystallites, preferentially oriented with (002), (110) and (101) parallel to the substrate surface, have a crystalline structure with small concentration of structural defects [2,9].

Additional information on the structural characteristics of studied films can be obtained from the calculation of strain and residual stress.

The strain in $\mathrm{ZnO}$ thin films along $c$-axis perpendicular to substrate surface can be calculated using the following expression [31]:

$$
\varepsilon_{2}[\%]=\frac{c-c_{0}}{c_{0}} \times 100,
$$

where $c$ denotes the lattice parameter of hexagonal (wurtzite) cell of the $\mathrm{ZnO}$ films, $c_{0}$ is the unstrained lattice parameter for bulk $\mathrm{ZnO}\left(c_{0}=5.2066 \AA[24]\right)$.

The residual stress, $\sigma$, in $\mathrm{ZnO}$ thin film can be determined by relationship [32]:

$$
\sigma=\frac{2 c_{13}^{2}-c_{33}\left(c_{11}+c_{12}\right)}{2 c_{13}} \frac{c-c_{0}}{c_{0}},
$$

where $c_{i j}$ represent elastic stiffness constants for $\mathrm{ZnO}$ single crystals; $c_{11}=208.8 \mathrm{GPa}, c_{33}=213.8 \mathrm{GPa}$, $c_{12}=119.7 \mathrm{GPa}$, and $c_{13}=104.2 \mathrm{GPa}$ [27].

Using indicated values for $c_{i j}$ coefficients of the residual stress value can be estimated from [29]:

$$
\sigma=-232.8 \frac{c-c_{0}}{c_{0}}[\mathrm{GPa}] \text {. }
$$

The $c$-parameter values and the calculated stress, using Eq. (9), for some studied samples are indicated in Table IV.

The residual stress of samples OXZ.60.07 and OXZ.60.09 is tensile and for samples OXZ.70.10 and OXZ.70.11 is compressive. Consequently, the annealing at $700 \mathrm{~K}$ determines the elimination of tensile film stress and improves film crystallinity (as also the XRD studies confirm).

The surface microstructure of the films was investigated by an ex situ atomic force microscopy (AFM). The AFM images depicted in Fig. 3 show that the film mi-

\section{TABLE V}

Values of strain and residual stress for some studied samples.

\begin{tabular}{c|c|c|c|c|c|c}
\hline \hline Sample & $\begin{array}{c}d \\
{[\mathrm{~nm}]}\end{array}$ & $\begin{array}{c}T_{0} \\
{[\mathrm{~K}]}\end{array}$ & $\begin{array}{c}\tau_{0} \\
{[\mathrm{~min}]}\end{array}$ & $\begin{array}{c}c \\
{[\AA]}\end{array}$ & $\begin{array}{c}\varepsilon \times 10^{-3} \\
{[\%]}\end{array}$ & $\begin{array}{c}\sigma \\
{[\mathrm{GPa}]}\end{array}$ \\
\hline OXZ.60.07 & 780 & 600 & 20 & 5.193 & -2.6 & 0.605 \\
OXZ.60.09 & 900 & 600 & 20 & 5.192 & -2.8 & 0.651 \\
OXZ.70.10 & 1020 & 700 & 30 & 5.208 & 2.6 & -0.605 \\
OXZ.70.11 & 1100 & 700 & 30 & 5.204 & -0.4 & 0.093 \\
\hline
\end{tabular}

$d$, film thickness; $T_{0}$, oxidation temperature; $\tau_{0}$, oxidation time; $c$, lattice parameter of the hexagonal (wurtzite) structure; $\varepsilon$, strain along $c$-axis; $\sigma$, residual stress

crostructure is characterized by high-density columnar structure with low surface roughness. It can be observed that by increasing film thickness the crystallites are getting larger and begin to agglomerate and to form clusters. The average roughness, $R_{\mathrm{a}}$, was calculated by expression

$$
R_{\mathrm{a}}=(1 / N) \sum_{i=1}^{N}\left|z_{\mathrm{m}}-z_{\mathrm{i}}\right|,
$$

where $N$ is the number of deviations in height $\left(z_{i}\right)$ from the profile mean value $\left(z_{\mathrm{m}}\right)$.

The average surface roughness, $R_{\mathrm{a}}$, varied between $35 \mathrm{~nm}$ and $108 \mathrm{~nm}$, depending on film thickness. The AFM images show the differences between the surfaces roughness of the films oxidized at different temperatures.

AFM images show that the films are grain-like and crystallite size increases with increasing film thickness.

The obtained results for two studied samples are shown in Fig. 3. It is noted from these images that in the film annealed at $600 \mathrm{~K}$ the crystallite size becomes much broader than these annealed at $700 \mathrm{~K}$. This is in good agreement with crystallite size determined by the Debye-Scherrer expression (Table III).

\subsection{Optical characteristics}

The typical optical transmission spectra of two investigated $\mathrm{ZnO}$ thin film samples in the wavelength range between $300 \mathrm{~nm}$ and $1800 \mathrm{~nm}$ are presented in Fig. 4 .

It is known that optical transmission of the thin films depends on the thickness and the surface morphology of the respective films. Generally, as the film is thinner and its surface morphology is more uniform, the transmission coefficient of the film becomes higher.

The average transmittance in the domain from 700 to $1600 \mathrm{~nm}$ of spectra was ranged between $80 \%$ and $90 \%$ for all studied samples. With increasing film thickness, the transmission coefficient decreases, due to the thickness effect [22].

It can be observed from Fig. 4 that transmission spectra present a sharp edge at a wavelength corresponding to the forbidden energy gap of $\mathrm{ZnO}$ crystals [2, 9, 13, 22]. This behavior shows that the studied films have a stoichiometric and homogeneous structure [11, 30]. With increase of the oxidation time, the transmission edge becomes sharper, indicating an improvement in the crystalline structure of the films. It was also established that 


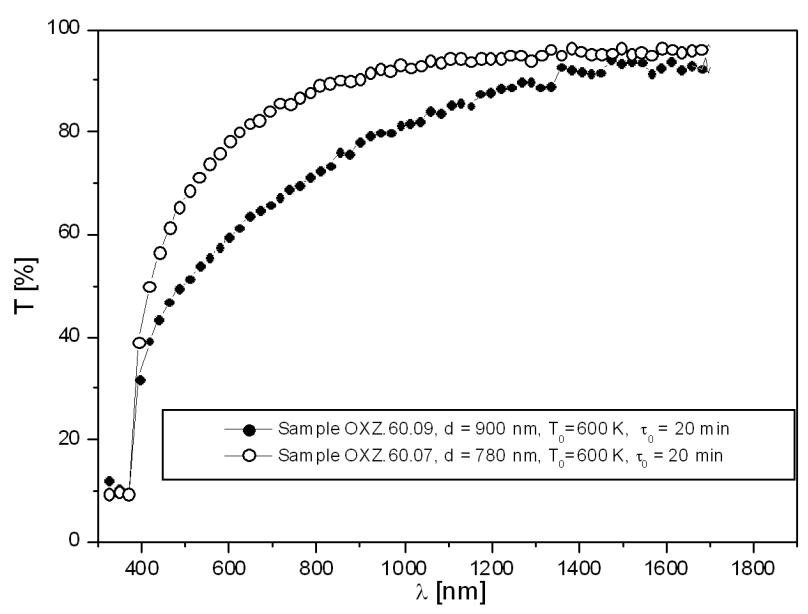

Fig. 4. Typical transmission spectra for $\mathrm{ZnO}$ thin films (samples OXZ.60.07 and OXZ.60.09).

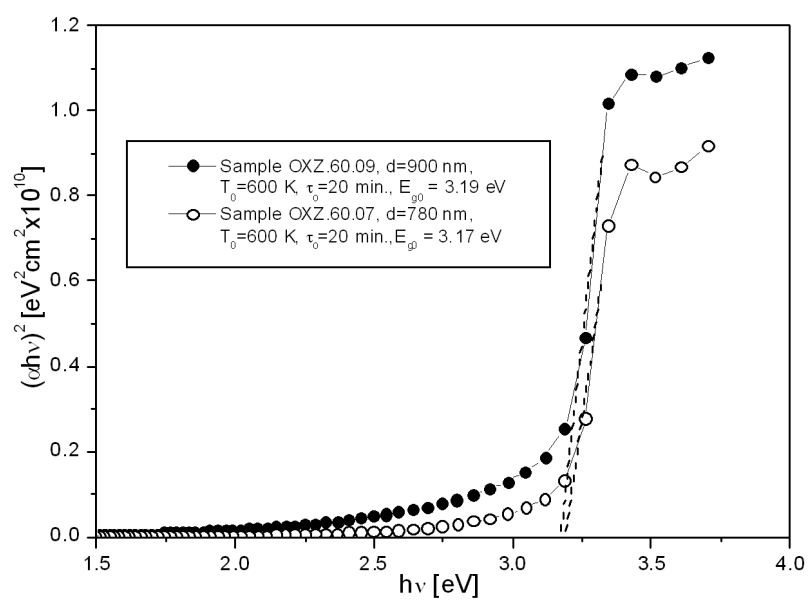

Fig. 5. The plots of $(\alpha h \nu)^{2}$ vs. photon energy, $h \nu$, for two ZnO thin films (samples OXZ.60.07 and OXZ.60.09).

the increase of the oxidation time results in an important decrease of the transmission coefficient.

The absorption coefficient was calculated taking into account Eq. (1). It is well known that investigation of the fundamental absorption edge of the semiconducting thin films provides important information on the characteristics of interband electronic transitions and the value of optical energy bandgap [13, 22].

Near the absorption edge, the energy dependence of the absorption coefficient, $\alpha$, can be described by the following expressions proposed by Tauc [9, 28]:

— for the allowed direct transitions (neglecting exciton effect)

$$
\alpha h \nu=A_{\mathrm{d}}\left(h \nu-E_{\mathrm{g} 0}\right)^{1 / 2}
$$

- for the forbidden direct transitions (also neglecting exciton effect)

$$
\alpha h \nu=A_{\mathrm{i}}\left(h \nu-E_{\mathrm{g} 0}\right)^{3 / 2} .
$$

In Eqs. (11) and (12), $h \nu$ is incident photon energy, $E_{\mathrm{g} 0}$ denotes the optical energy band gap (for wave vector $\boldsymbol{k}=0$ ), and $A_{\mathrm{d}}$ and $A_{\mathrm{i}}$ are characteristic parameters (independent of photon energy) for respective transitions [22].

$\mathrm{ZnO}$ crystals are characterized by direct optical transitions [2-4]. Consequently, according to Eq. (11), in the vicinity of the fundamental (intrinsic) absorption edge $(\alpha h \nu)^{2}$ linearly depends upon the photon energy $h \nu$. Thus, by extrapolating the linear portions of the $(\alpha h \nu)^{2}=f(h \nu)$ dependences to $(\alpha h \nu)^{2} \rightarrow 0$ one can determine the value of $E_{\mathrm{g} 0}$ for direct transitions. These dependences are presented in Fig. 5. The obtained values of the band-gap width, $E_{\mathrm{g} 0}$, ranged between $3.17 \mathrm{eV}$ and $3.19 \mathrm{eV}$. These values are in good agreement with those reported for bulk $\mathrm{ZnO}$ samples [2, 7, 33, 34].

\section{Conclusions}

It was found that polycrystalline $\mathrm{ZnO}$ thin films with high transmission coefficient $(80 \%-90 \%$ in visible spectral range) and hexagonal (wurtzite) structure, highly oriented with $c$-axis perpendicular to the substrate surface, can be prepared by thermal oxidation of vacuum evaporated zinc metallic films.

The film thickness was varied in the range from $780 \mathrm{~nm}$ to $1150 \mathrm{~nm}$.

The structural characteristics (crystallite size, Zn-O bond length, texture coefficient, strain, etc.) of the films studied by XRD, AFM and X-ray photoelectron spectroscopy (XPS) show a good crystallinity columnar growth and a smooth surface.

In the wavelength range from $600 \mathrm{~nm}$ to $1600 \mathrm{~nm}$, the transmission coefficient is generally over $80 \%$. The optical band-gap energy calculated from absorption spectra (considering allowed direct transitions) were in the range $3.17-3.19 \mathrm{eV}$.

\section{References}

[1] H.L. Hartnagel, A.L. Dawar, A.K. Jain, C. Jagadish, Semiconducting Transparent Thin Films, Institute of Physics Publishing, Bristol 1995.

[2] Polycrystalline Semiconductors: Physical Properties and Applications, Ed. G. Harbeke, Springer-Verlag, Berlin 1985.

[3] W.L. Dang, Y.Q. Fu, J.K. Luo, A.J. Flewitt, W.I. Milne, Superlattices Microstruct. 42, 89 (2007).

[4] Zinc Oxide Bulk, Thin Films and Nanostructures Processing, Properties and Applications, Eds. C. Jagadiste, S.Y. Pearson, Elsevier, Amsterdam 2006.

[5] A.P. Râmbu, G.I. Rusu, Superlattices Microstruct. 47, 300 (2010).

[6] Y.G. Wang, J. Appl. Phys. 44, 354 (2003).

[7] G.G. Rusu, A.P. Rambu, M. Rusu, J. Optoelectron Adv. Mater. 10, 339 (2008).

[8] Sunglac Cho, Appl. Phys. Lett. 75, 2761 (1999). 
[9] Polycrystalline and Amorphous Thin Films and Devices, Ed. L.L. Kazmerski, Academic Press, New York 1980.

[10] S.W. Xue, X.T. Zu, W.L. Zhou, H.X. Deng, X. Xiang, L. Zhang, H. Deng, J. Alloys Comp. 448, 21 (2008).

[11] E.K. Kim, S. Kim, Superlattices Microstruct. 42, 343 (2007).

[12] P. Bhattacharya, R.R. Das, R.S. Katiyar, Thin Solid Films 564, 447 (2004).

[13] K.L. Chopra, Thin Film Phenomena, McGraw-Hill, New York 1969.

[14] Z.W. Li, W. Gao, R.J. Reeves, Surf. Coat. Technol. 198, 319 (2005).

[15] E.S. Tuzemen, S. Eker, H. Kavak, R. Esen, Appl. Surf. Sci. 255, 6195 (2009).

[16] Q.P. Wang, X.J. Zhang, C.Q. Wang, S.H. Chen, X.H. Wu, H.L. Ma, Appl. Surf. Sci. 254, 5100 (2008).

[17] K.C. Kim, E.K. Kim, Y.S. Kim, Superlattices Microstruct. 42, 246 (2007).

[18] G.G. Rusu, M. Rusu, Solid State Commun. M6, 363 (2000).

[19] G.I. Rusu, M.E. Popa, G.G. Rusu, I. Salaoru, Appl. Surf. Sci. 218, 222 (2003).

[20] B.D. Cullity, Elements of X-ray Diffraction, Addison-Wesley, Reading, Massachusetts 1978, p. 356.

[21] American Standard for Testing Materials, X-ray Powder Diffraction Data, File Card 5-0664.
[22] J.N. Pankove, Optical Processes in Semiconductors, Dover, New York 1971.

[23] G.I. Rusu, M. Diciu, C. Pirghie, M.E. Popa, Appl. Surf. Sci. 253, 9500 (2007).

[24] T. Yamamoto, T. Shiosaki, A. Kawabata, J. Appl. Phys. 51, 3113 (1980).

[25] H. Metin, R. Esen, Semicond. Sci. Technol. 18, 647 (2003).

[26] S.J. Pearton, D.P. Norton, I.Y. Heo, T. Steiner, J. Vac. Sci. Technol. B 22, 155504 (2004).

[27] C.S. Barret, F.B. Massalski, Structure of Metals, Pergamon Press, Oxford 1980.

[28] J. Tauc, R. Grigorovici, Y. Vancu, Phys. Status Solidi 15, 627 (1966)

[29] J. Mass, P. Bhattacharya, R.S. Katiyar, Mater Sci. Eng. B 9, 103 (2003).

[30] J. Benn, P.R. Manyon, V.K. Vaedyan, Bull. Mater. Sci. 28, 487 (2005).

[31] H.C. Ong, A.X.E. Zhu, G.T. Du, Appl. Phys. Lett. 80, 941 (2002).

[32] C. Wang, P. Zhang, J. Yue, Y. Zhang, L. Zheng, Physica B 403, 2235 (2008).

[33] M. Smirnov, C. Baban, G.I. Rusu, Appl. Surf. Sci. 256, 2405 (2010).

[34] J.K. Furdina, J. Appl. Phys. 64, 29 (1988). 